\title{
Infective endocarditis at a tertiary-care hospital in China
}

\author{
Lulu Ma' ${ }^{1}$ Ying $\mathrm{Ge}^{2}$, Haobo $\mathrm{Ma}^{3}$, Bo Zhu ${ }^{1 *+}$ (D) and Qi Miao ${ }^{4{ }^{*+}}$
}

\begin{abstract}
Background: The aim of this study was to describe the clinical features and outcome of infective endocarditis at a general hospital in China and to identify the risk factors associated with in-hospital mortality.

Methods: A retrospective study was conducted and all patients diagnosed with definite or possible infective endocarditis between January 2013 and June 2018 according to the modified Duke criteria were included.

Results: A total of 381 patients were included. The mean age was 46 years old and $66.9 \%$ patients were male patients. Community acquired IE was the most common type of infective endocarditis and Viridans Group Streptococci (37.5\%) was still the most common causative pathogen. The microbial etiology of infective endocarditis varied with location of acquisition. 97 (25.5\%) patients had culture-negative infective endocarditis. Vegetations were detected in $85 \%$ patients and mitral valve was the most common involved valve. Operations were performed in $72.7 \%$ patients and in-hospital mortality rate was $8.4 \%$. The risk factors of in-hospital mortality were age old than 70 years old, heart failure, stroke and medical therapy.

Conclusions: Older age, heart failure, stroke and medical therapy were risk factors of in-hospital mortality. Infective endocarditis, were mainly caused by Viridans Group Streptococci, characterized by younger patients and lower mortality rate in China.
\end{abstract}

Keywords: Infective endocarditis, In-hospital mortality, Viridans group streptococci

\section{Background}

Infective endocarditis (IE) is an uncommon infective disease. Heart failure and embolisms of vegetations to the brain and other organs are life-threatening complications. Despite advances in diagnosis, medical and surgical treatment, the variability of disease presentation is a challenge to clinicians and the mortality remains high. The in-hospital mortality rate is $15-20 \%[1,2]$ and the

\footnotetext{
* Correspondence: zhubo@pumch.cn; miaogipumc@hotmail.com

${ }^{\dagger}$ Bo Zhu and Qi Miao contributed equally to this work.

'Department of Anesthesiology, Peking Union Medical College Hospital, Chinese Academy of Medical Sciences and Peking Union Medical College, Beijing 100730, China

${ }^{4}$ Department of Cardiac Surgery, Peking Union Medical College Hospital, Chinese Academy of Medical Sciences and Peking Union Medical College, Beijing 100730, China

Full list of author information is available at the end of the article
}

one-year mortality is 40\% [2-4]. Early diagnosis, antibiotic therapy or surgery is necessary.

Few studies have been performed to describe the characteristics of IE in China, the aim of this study was to describe the clinical characteristics of IE in a single center in China and to identify the risk factors associated with in-hospital mortality.

\section{Methods}

A retrospective study was conducted at Peking Union Medical College Hospital. This study has been granted an exemption from requiring ethics approval according to "The ethics committee of Peking Union Medical College Hospital".

Patients who were diagnosed with definite or possible IE according to modified Duke criteria between January 2013 and June 2018 were included. Medical records were reviewed and clinical information which included

(c) The Author(s). 2020 Open Access This article is licensed under a Creative Commons Attribution 4.0 International License, which permits use, sharing, adaptation, distribution and reproduction in any medium or format, as long as you give appropriate credit to the original author(s) and the source, provide a link to the Creative Commons licence, and indicate if changes were made. The images or other third party material in this article are included in the article's Creative Commons licence, unless indicated otherwise in a credit line to the material. If material is not included in the article's Creative Commons licence and your intended use is not permitted by statutory regulation or exceeds the permitted use, you will need to obtain permission directly from the copyright holder. To view a copy of this licence, visit http://creativecommons.org/licenses/by/4.0/ The Creative Commons Public Domain Dedication waiver (http://creativecommons.org/publicdomain/zero/1.0/) applies to the data made available in this article, unless otherwise stated in a credit line to the data. 
age, gender, comorbidities, clinical signs and symptoms, possible source of infections, previous history of IE, valves involved, laboratory and echocardiographic findings and treatment was retrospectively collected.

Community -acquired IE was that diagnosed at the time of admission or $\leq 48 \mathrm{~h}$ of admission. Health care associated IE included nosocomial and non-noscomial health care-associated IE. Nosocomial IE was defined as IE developing in patients hospitalized for more than $48 \mathrm{~h}$ without manifestations of IE before admission. Nonnosocomial health care-associated IE was defined if signs or symptoms of IE developed before hospitalization in patients with extensive health care contact, including (1) intravenous therapy, wound care or specialized nursing care at home within the 30 days before the onset of IE, (2) visiting a hospital or hemodialysis clinic or receiving intravenous chemotherapy within the 30 days before the onset of IE, (3) hospitalization in an acute care hospital for $\geq 2$ days in the 90 days before the onset of IE, (4) staying in a nursing home or long-term care facility [5].

Systemic use of corticosteroids or chemotherapy for more than 1 month was defined as immunosuppressive therapy. Cancer was defined as those with active disease or on chemotherapy. Immunological phenomena included glomerulonephritis, Osler's nodes, Roth spots and rheumatoid factor positivity. Vascular phenomena included major arterial emboli, septic pulmonary infarcts, mycotic aneurysm, intracranial hemorrhage, conjunctival hemorrhages and Janeway's lesions. Antimicrobial therapy was based on either the American Heart Association Guidelines [6] or the European Society of Cardiology guidelines [7]. Antibiotics started as soon as the results of blood cultures had been acquired, and 4-6 weeks was usually necessary. For acute ill patients with suspected IE, empiric therapy which covered staphylococci, streptococci and enterococci would initiate first. Once the pathogen was identified, the antibiotic treatment will be modified according to the pathogen, antimicrobial susceptibility pattern, severity of infection and also the type of IE. The indications of surgical intervention in our center included heart failure, recurrent embolic event, vegetation size $(>10 \mathrm{~mm})$, persistent bacteremia, paravalvular complications, prosthetic valve endocarditis, and microorganism of fungi or high resistant organisms. In-hospital mortality was defined as death occurring during hospitalization for IE.

Statistical analyses were performed with SPSS software, version 19.0 (SPSS Inc., Chicago, Illinois). Quantitative data was shown as mean $\pm \mathrm{SD}$. Categorical variables were summarized using frequency and percentages. Student $t$ test was used to compare variables between two groups. Chi-square test was used to compare categorical variables. Logistic regression analysis was performed to examine correlation of variables to in-hospital mortality. $P$ value $<0.05$ (2 -sided) was considered statistically significant.

\section{Results}

Three hundred eighty-one patients who were diagnosed with definite IE or possible IE were included. Community acquired IE (87.4\%) was the most common type of IE, followed by non-nosocomial health care associated IE (6.6\%) and nosocomial health care associated IE (6.0\%) (Table 1). Native valve involvement was detected in $352(92.4 \%)$ patients, followed by prosthetic valve related IE (6.8\%) and cardiac device -relate IE (0.8\%). There were 291 cases $(75.8 \%)$ of left-side IE and 54 cases (14.1\%) of right-side IE.

The demographic characteristics were summarized in Table 2. The mean age was 46 years old and 255 patients (66.9\%) were male. Age and sex distributions of patients were shown in Fig. 1.

Degenerative valve disease and congenital heart disease were the common underlying cardiac diseases. Bicuspid aortic valve (50 cases, $13.1 \%$ ) and mitral valve prolapse were (28 cases, $7.3 \%$ ) were the most common degenerative valve disease. Congenital heart disease was found in 68 cases, among which there were 29 cases of ventricular septal defect and 21 cases of patent ductus arteriosus.

Twenty-seven patients (7.1\%) had dental procedure before the onset of the symptoms and 12 of them had prophylactic antibiotic treatment. There are 38 (10.0\%) postsurgical cases, with 13 cases of cardiac surgeries and 25 cases of non-cardiac surgeries. 31 (86.5\%) of them had antibiotics after operations. Three patients had a history of trauma and intravenous drug use (1 case) was uncommon in our cohort.

There was no difference in age and sex distribution among community acquired IE, non-nosocomial health care associated IE and nosocomial health care associated IE. The proportion of degenerative valve disease was higher in community acquired IE $(P=0.024)$, immunocompromised state was more common in nosocomial IE $(P<0.001)$, while dialysis was more common in nonnosocomial IE $(P<0.001)$.

Blood cultures were taken to determine the causative microorganism. Serologic tests and valve cultures were also performed in a small portion of patients. 97 (25.5\%) patients had negative culture result. Gram positive

Table 1 Type of IE and microbiologic etiology of IE

\begin{tabular}{ll}
\hline Type of IE & \\
Community-acquired & $333(87.4 \%)$ \\
Nosocomial health care associated & $23(6.0 \%)$ \\
Non-nosocomial health care associated & $25(6.6 \%)$ \\
Valve involved & \\
Native valve involvement & $352(92.4 \%)$ \\
Prosthetic valve involvement & $26(6.8 \%)$ \\
Cardiac device-related IE & $3(0.8 \%)$ \\
\hline
\end{tabular}


Table 2 Demographic characteristics and predisposing conditions in 381 patients

\begin{tabular}{|c|c|c|c|c|c|}
\hline Variables & Total & Community acquired $(n=333)$ & Non-nosocomial $(n=25)$ & Nosocomial $(n=23)$ & $P$ \\
\hline Age, years & $46 \pm 16$ & $46 \pm 16$ & $46 \pm 17$ & $52 \pm 14$ & 0.275 \\
\hline Male & $255(66.9 \%)$ & $217(65.2 \%)$ & $20(80 \%)$ & $18(78.3 \%)$ & 0.155 \\
\hline \multicolumn{6}{|l|}{ Predisposing medical disease } \\
\hline Degenerative valve disease & $82(21.5 \%)$ & 78 (23.4\%) & $4(16 \%)$ & $0(0 \%)$ & 0.024 \\
\hline Hypertension & $77(20.2 \%)$ & $61(18.3 \%)$ & $6(24 \%)$ & $10(43.5 \%)$ & 0.013 \\
\hline Congenital heart disease & $68(17.8 \%)$ & $63(18.9 \%)$ & $3(12 \%)$ & $2(8.7 \%)$ & 0.344 \\
\hline Diabetes mellitus & $34(8.9 \%)$ & $27(8.1 \%)$ & $3(12 \%)$ & $4(17.4 \%)$ & 0.274 \\
\hline Alcohol abuse & $26(6.8 \%)$ & $21(6.3 \%)$ & $4(16 \%)$ & $1(4.3 \%)$ & 0.159 \\
\hline Rheumatic heart disease & $23(6.0 \%)$ & $20(6.0 \%)$ & $1(4 \%)$ & $2(8.7 \%)$ & 0.791 \\
\hline Immunocompromised state & $22(5.8 \%)$ & $10(3.0 \%)$ & $3(12 \%)$ & $9(39.1 \%)$ & $<0.001$ \\
\hline Coronary heart disease & $20(5.2 \%)$ & $17(5.1 \%)$ & $2(8 \%)$ & $1(4.3 \%)$ & 0.806 \\
\hline Cancer & $13(3.4 \%)$ & $10(3.0 \%)$ & $1(4 \%)$ & $2(8.7 \%)$ & 0.342 \\
\hline History of IE & $10(2.6 \%)$ & $9(2.7 \%)$ & $1(4 \%)$ & $0(0 \%)$ & 0.666 \\
\hline Hypertrophic cardiomyopathy & $7(1.8 \%)$ & $7(2.1 \%)$ & $0(0 \%)$ & $0(0 \%)$ & 0.598 \\
\hline Dialysis & $5(1.3 \%)$ & $0(0 \%)$ & $4(16 \%)$ & $1(4.3 \%)$ & $<0.001$ \\
\hline Pregnancy & $2(0.5 \%)$ & $2(0.6 \%)$ & $0(0 \%)$ & $0(0 \%)$ & 0.865 \\
\hline
\end{tabular}

organisms were the most common causative microorganism. The microbial etiology of IE varied with location of acquisition, with a higher proportion of Viridans group Streptococci among patients with community acquired infection. (Table 3).

Fever was the most common clinical manifestation. Heart failure was observed in $70(18.4 \%)$ patients. Vascular phenomena $(42.8 \%)$ were more common than immunological phenomena (40.0\%). Abscess, which included cerebral, splenic, pulmonary and vertebral abscess was found in $40(10.5 \%)$ patients. (Table 4).

All patients had echocardiography and $85 \%$ had echocardiographic evidence of vegetation. 57(15\%) patients had both transthoracic and transesophageal echocardiography. Mitral valve was the most common involved (36.5\%), followed by the aortic valve (33.3\%). New severe mitral regurgitation and aortic regurgitation were detected in $71(18.6 \%)$ and $77(20.2 \%)$ patients, respectively. Paravascular complications, which included paravascular fistula and abscess were observed in 47 patients.

Operation was performed in $277(72.7 \%)$ patients, and 29 patients had emergent operations. Among patients who did not have operation, 53 patients recovered after medical treatment. Forty-seven patients had surgical indications, and patients' refuse (34 patients), cerebral infarction (10 patients), surgical difficult (2 patients), hemodynamic instability (2 cases) and other medical causes (2 patients) are reasons for no surgery. Inhospital mortality was $8.4 \%$ (32 patients). The inhospital mortality rate in community acquired IE, nonnosocomial health care associated IE and nosocomial health care associated IE was 6.3, 12 and $34.8 \%$

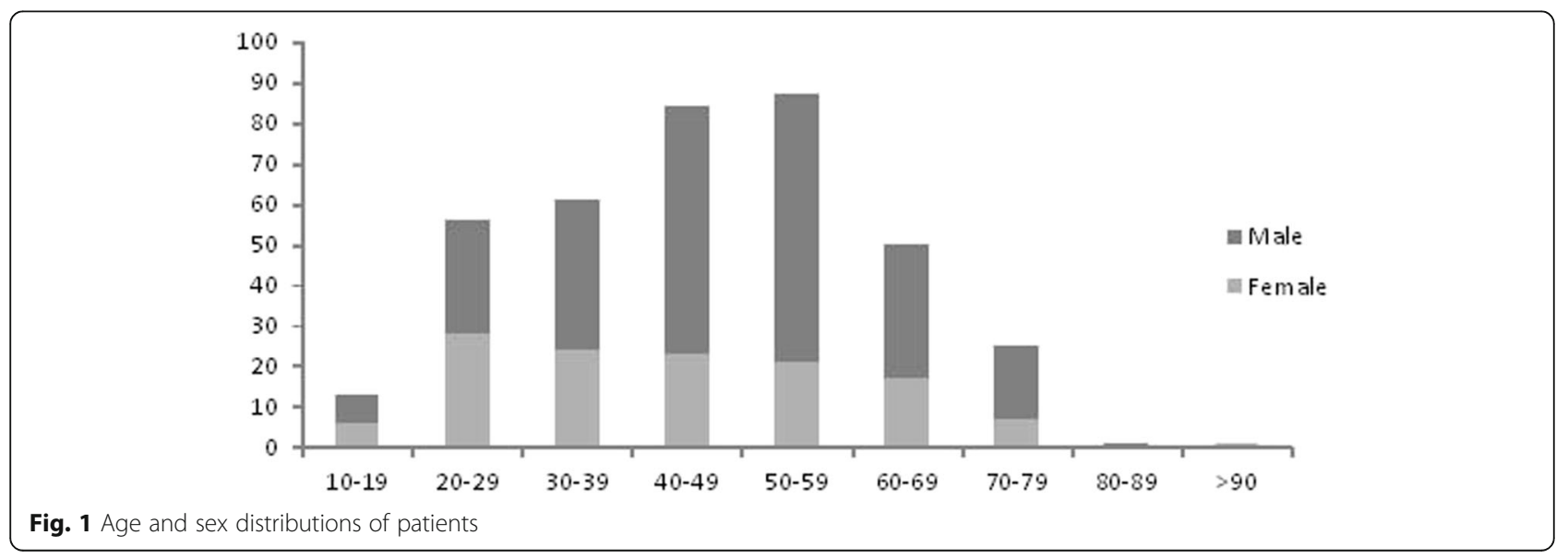


Table 3 Causative pathogens and acquisition of infective endocarditis

\begin{tabular}{|c|c|c|c|c|c|}
\hline Causative pathogen & Total $(n=381)$ & Community acquired $(n=333)$ & Non-nosocomial I $(n=25)$ & Nosocomial $(n=23)$ & $P$ \\
\hline \multicolumn{6}{|l|}{ Gram-positive bacteria } \\
\hline Viridans group streptococci & $143(37.5 \%)$ & $134(40.2 \%)$ & $8(32 \%)$ & $1(4.3 \%)$ & 0.002 \\
\hline Staphylococcus aureus & $30(7.9 \%)$ & $21(6.3 \%)$ & $5(20 \%)$ & $4(17.3 \%)$ & 0.011 \\
\hline MRSA & $10(2.6 \%)$ & $8(2.4 \%)$ & $1(4 \%)$ & $1(4.3 \%)$ & 0.772 \\
\hline MSSA & $20(5.2 \%)$ & $13(3.9 \%)$ & $4(16 \%)$ & $3(13.0 \%)$ & 0.007 \\
\hline CNS & $12(3.1 \%)$ & $8(2.4 \%)$ & $2(8 \%)$ & $2(8.7 \%)$ & 0.088 \\
\hline Enterococcus faecalis & $11(2.9 \%)$ & $8(2.4 \%)$ & $3(12 \%)$ & $0(0 \%)$ & 0.015 \\
\hline Streptococcus bovis & $6(1.6 \%)$ & $6(1.8 \%)$ & $0(0 \%)$ & $0(0 \%)$ & 0.644 \\
\hline Other & $16(4.2 \%)$ & $14(4.2 \%)$ & $2(8 \%)$ & $0(0 \%)$ & 0.386 \\
\hline Gram-negative rods & $21(5.5 \%)$ & $16(4.8 \%)$ & $0(0 \%)$ & $5(21.7 \%)$ & 0.001 \\
\hline HAECK & $12(3.1 \%)$ & $11(3.3 \%)$ & $0(0 \%)$ & $1(4.3 \%)$ & 0.623 \\
\hline Rickettsia & $4(1.0 \%)$ & $4(1.2 \%)$ & $0(0 \%)$ & $0(0 \%)$ & 0.747 \\
\hline TB & $1(0.26 \%)$ & $1(0.3 \%)$ & $0(0 \%)$ & $0(0 \%)$ & 0.930 \\
\hline Fungi & $6(1.6 \%)$ & $3(0.9 \%)$ & $1(4 \%)$ & $2(8.7 \%)$ & 0.009 \\
\hline Others & $12(3.1 \%)$ & $12(3.6 \%)$ & $0(0 \%)$ & $0(0 \%)$ & 0.409 \\
\hline Polymicrobial & $10(2.6 \%)$ & 7 (2.1\%) & $2(8 \%)$ & $1(4.3 \%)$ & 0.178 \\
\hline Culture negative & 97 (25.5\%) & 88 (26.4\%) & $2(8 \%)$ & 7 (30.4\%) & 0.106 \\
\hline
\end{tabular}

Table 4 Clinical manifestation and ultrasonic findings in 381 patients

\begin{tabular}{ll}
\hline Clinical manifestation & \\
\hline First clinical manifestation<1 month & $133(34.9 \%)$ \\
Fever & $367(96.3 \%)$ \\
New murmur & $157(41.2 \%)$ \\
Vascular phenomena & $163(42.8 \%)$ \\
$\quad$ Stoke & $88(23.1 \%)$ \\
Heart failure & $70(18.4 \%)$ \\
Abscess & $40(10.5 \%)$ \\
Anemia & $259(68 \%)$ \\
Immunological phenomena & $118(31 \%)$ \\
Vegetation & $325(85 \%)$ \\
Involved valve & \\
Aortic valve & $127(33.3 \%)$ \\
Mitral valve & $139(36.5 \%)$ \\
Tricuspid valve & $32(8.4 \%)$ \\
Pulmonary valve & $14(3.7 \%)$ \\
Others & $7(1.8 \%)$ \\
Multi & $40(10.5 \%)$ \\
Intra-cardiac implantation & $2(0.5 \%)$ \\
New severe mitral regurgitation & $71(18.6 \%)$ \\
New severe aortic regurgitation & $77(20.2 \%)$ \\
Paravalvular complication & $47(12.3 \%)$ \\
\hline & $13(3.4 \%)$ \\
Abscess & $34(8.9 \%)$ \\
\hline
\end{tabular}

respectively. Multivariable regression analysis showed that age older than 70 years old, heart failure, stroke and medical therapy are risk factors of in-hospital mortality. (Table 5).

\section{Discussion}

This retrospective study described the epidemiological and clinical features of IE in a single center in China. The average age was 46 years old and Viridans group streptococci was still the most common pathogen. Surgical therapy was performed $72.7 \%$ patients. The risk factors of in-hospital mortality included age older than 70 years old, heart failure, stroke and medical therapy.

The mean age of patients in our cohort was 46 years old, which was younger than that in developed countries ranging from to 52.9 to 69.1 years old [8-10]. But the mean age in our cohort was older than another study conducted in China from 1998 to 2009 [11]. The reasons for increasing trend of age of IE patients in China were related to decreased rate of rheumatic heart disease and congenital heart disease, and increased rate of degenerative valve disease.

Blood culture was still the major criteria for infective endocarditis. Viridans group streptococci were the most common pathogen in our cohort, which was consistent with previous report in china, Laos and Japan [10-13]. However, Staphylococcus aureus was the most common causative pathogen in developed countries $[8,9,14]$. We also noticed the different causative pathogen varied with location of acquisition and Staphylococcus aureus was more common in health care associated IE. The reasons 
Table 5 Predictors of in-hospital mortality of IE patients

\begin{tabular}{|c|c|c|c|c|c|c|}
\hline & Survisors $(n=349)$ & Death $(n=32)$ & $p$ & OR & Multivariable regressi & \\
\hline Age (older than 70) & 19 & 8 & 0.002 & $4.583(1.861,11.285)$ & $3.887(1.072,14.096)$ & 0.039 \\
\hline Sex (Male/Female) & 230/119 & $25 / 7$ & 0.175 & $0.541(0.227,1.288)$ & & \\
\hline Rheumatic heart disease & 21 & 2 & 1.000 & $1.041(0.233,4.656)$ & & \\
\hline Degenerative valve disease & 49 & 1 & 0.100 & $0.197(0.026,1.480)$ & & \\
\hline Congenital heart disease & 66 & 2 & 0.090 & $0.286(0.067,1.226)$ & & \\
\hline Hypertrophy cardiomyopathy & 7 & 1 & 0.508 & $1.576(0.188,13.226)$ & & \\
\hline History of IE & 9 & 1 & 0.589 & $1.219(0.149,9.936)$ & & \\
\hline Hypertension & 64 & 13 & 0.005 & $3.047(1.431,6.488)$ & & \\
\hline DM & 28 & 6 & 0.053 & $2.646(1.005,6.965)$ & & \\
\hline Immunocompromised state & 15 & 7 & 0.001 & $6.235(2.328,16.694)$ & & \\
\hline dialysis & 2 & 3 & 0.005 & $17.948(2.882,111.761)$ & & \\
\hline cancer & 9 & 4 & 0.017 & $5.397(1.563,18.635)$ & & \\
\hline Health care associated IE & 37 & 11 & 0.001 & $4.417(1.974,9.881)$ & & \\
\hline Native valve involvement & 322 & 30 & 1.000 & $1.28(0.285,5.549)$ & & \\
\hline Prosthetic valve involvement & 24 & 2 & 1.000 & $1.108(0.250,4.916)$ & & \\
\hline Cardiac device-related IE & 3 & 0 & 1.000 & $0.991(0.982,1.001)$ & & \\
\hline Fever & 336 & 31 & 1.000 & $0.834(0.106,6.587)$ & & \\
\hline New murmur & 142 & 15 & 0.574 & $1.286(0.622,2.660)$ & & \\
\hline Heart failure & 52 & 18 & 0.000 & $7.343(3.441,15.671)$ & $7.955(2.966,21.338)$ & 0.000 \\
\hline Vascular phenomena & 144 & 19 & 0.061 & $2.081(0.996,4.348)$ & & \\
\hline stroke & 71 & 17 & 0.000 & $4.212(2.009,8.830)$ & $4.190(1.669,10.519)$ & 0.002 \\
\hline Immunological phenomena & 113 & 5 & 0.070 & $0.387(0.145,1.031)$ & & \\
\hline Viridans group streptococci & 136 & 7 & 0.059 & $0.43990 .185,1.042)$ & & \\
\hline \multicolumn{7}{|l|}{ Staphylococcus aureus } \\
\hline MRSA & 9 & 1 & 0.589 & $1.219(0.149,9.936)$ & & \\
\hline MSSA & 18 & 2 & 0.680 & $1.226(0.271,5.538)$ & & \\
\hline CNS & 11 & 1 & 1.000 & $0.991(0.124,7.933)$ & & \\
\hline Enterococcus faecalis & 10 & 1 & 1.000 & $1.094(0.135,8.826)$ & & \\
\hline Streptococcus bovis & 5 & 1 & 0.411 & $0.451(0.051,3.979)$ & & \\
\hline HAECK & 12 & 0 & 0.610 & $0.966(0.947,0.985)$ & & \\
\hline Rickettsia & 4 & 0 & 1.000 & $0.989(0.977,1.000)$ & & \\
\hline TB & 1 & 0 & 1.000 & $0.997(0.992,1.003)$ & & \\
\hline Fungi & 3 & 3 & 0.009 & $11.931(2.304,61.787)$ & & \\
\hline Polymicrobial & 8 & 2 & 0.201 & $2.842(0.577,13.988)$ & & \\
\hline Vegetation & 298 & 27 & 0.798 & $0.924(0.340,2.511)$ & & \\
\hline Aortic valve & 117 & 10 & 0.847 & $0.901(0.413,1.966)$ & & \\
\hline Mitral valve & 127 & 12 & 1.000 & $1.049(0.496,2.216)$ & & \\
\hline Tricuspid valve & 31 & 1 & 0.500 & $0.331(0.044,2.507)$ & & \\
\hline Pulmonary valve & 14 & 0 & 0.618 & $0.960(0.940,0.981)$ & & \\
\hline Multi valve involvement & 34 & 6 & 0.128 & $2.138(0.822,5.559)$ & & \\
\hline New severe mitral regurgitation & 48 & 7 & 0.198 & $1.756(0.720,4.283)$ & & \\
\hline New severe aortic regurgitation & 59 & 6 & 0.806 & $1.134(0.447,2.877)$ & & \\
\hline Medical therapy & 81 & 23 & 0.000 & $0.118(0.053,0.266)$ & $6.854(2.632,17.848)$ & 0.000 \\
\hline
\end{tabular}


of low frequency of staphylococcus infection in our study were as follows. First, the majority of IE in our cohort was community-acquired IE and native valves were the most frequently involved valves. The prevalence of risk factors for Staphylococcus aureus-associated IE (for example, drug abuse, health care contact and invasive procedures) $[9,12]$ in our study was low. Second, Viridans group Streptococci was the common pathogen in patients with poor dental health. It reflects the poor dental hygiene in Chinese population [12].

Culture-negative IE remains a challenge in clinic. The possible reasons included exposure to slow-growing bacterium, non-infective endocarditis, administration of antibiotics before blood culture, right-side IE, cardiac device-related IE or IE associated with intravascular device or foreign bodies [15]. In our study, the incidence of negative blood culture was $25.5 \%$, which was higher than previous reports [8-10]. Previous antibiotic administration contributed to the higher incidence of negative blood culture in our study. Metagenomic analysis has recently been successfully used in detecting pathogens in culture-negative infective endocarditis $[16,17]$, however more researches are required to prove its potential role in diagnosing culture-negative infective endocarditis.

Vegetations were detected in $85 \%$ patients in our study, which was similar to previous reports $[9,10]$. Transthoracic or transesophageal echocardiography is the mainstay in diagnosis of IE. The possibilities of no detection of vegetations were as following. First, the size of vegetation may be too small to de detected, and transesophageal echocardiography was not performed in all patients. Second, vegetations may disappear due to embolism. Third, antibiotic therapy had started before echocardiography.

Surgical therapy was performed in $72.7 \%$ patients which was higher than previous reports [8-10]. The indications of surgical intervention in our center were consistent with the recommendations from American Heart Association [6] and ESC guideline [7]. The majority of patients in our study were referred for surgical therapy from other hospitals was the main reason for this high percentage of patients being operated. And the average age of our cohort was younger than that in developed countries, and elderly patients with IE were less likely to have surgical treatment due to higher risk [18].

The overall in-hospital mortality rate was $8.4 \%$, which was lower than previous reports [8-10]. However, the in-hospital mortality rate of non-nosocomial health care associated IE and nosocomial health care associated IE was 12 and $34.8 \%$ respectively. Patients' characteristics, complications of IE, microorganism and the echocardiographic findings can all influence the prognosis [7]. The possible reasons which contributed the lower in-hospital mortality in our study were as followings. First, the average age of our study is younger than previous studies. And the mortality rate in elderly patients with IE was high [18]. Second, the main pathogen was Viridans group Streptococci in our cohort, while the proportions of Staphylococcus aureus and Fungi were low. Streptococcal IE was associated with a decreased risk of inhospital mortality [9]. Third, the majority of IE was community acquired IE in our study, while health-care related IE was the independent predictors of in-hospital mortality [8]. Besides these, native valve was the most common involved. Patients undergoing surgical treatment for prosthetic valve endocarditis had a higher 30day and 1-year mortality, when compared to native valve endocarditis [19]. The proportion of congenital heart disease, which was associated with better outcome than other forms of IE [7], was higher in our study [9, 10]. The last but not the least was the high rate of surgical treatment. Better prognosis had been reported in IE patients with a higher rate of valvular surgery [20,21].

Multivariable regression analysis showed older age, heart failure, stroke and medical therapy were independent risk factors of in-hospital mortality. Among these factors, heart failure had the highest odds ratio. Some studies have also confirmed that these factors were associated with in hospital mortality $[8,22-26]$. And perivascular abscess [19], diabetes mellitus [27, 28], or acute renal failure $[26,29]$ have also been reported to be the risk factors of high mortality. Interestingly, medical therapy was associated with higher in-hospital mortality, which suggested the protective role of surgical treatment. However, whether the surgical treatment was associated with better outcome or the higher proportion of surgical treatment contributed to the lower in-hospital mortality in our study still needs further research.

There were several limitations of this study. First, this was a retrospective study in a single center, the selection bias was unavoidable and the accuracy of data was limited. Second, the limited number of patients made the impossibility of generalization of our results. Third, this was a retrospective study, and long-term follow-up was lacking in the majority of patients.

\section{Conclusions}

Our study demonstrates that IE in China remains as a clinical challenge. Viridans group streptococci was still the most common pathogen and community acquired infection was the most acquisition of IE. Older age, heart failure, stroke and medical therapy were independent risk factors of in-hospital mortality.

\section{Abbreviations}

IE: Infective endocarditis; MRSA: Methicillin-resistant Staphylococcus aureus; MSSA: Methicillin-sensitive Staphylococcus aureus; CNS: Coagulative-negative Staphylococcus; HAECK Haemophilus, Aggregatibacter actinomycetemcomitans, Cardiobacterium hominis, Eikenella corrodens, and Kingella 


\section{Acknowledgements}

None.

\section{Authors' contributions}

$L M$ - acquisition of data and the preparation of the manuscript. Y Gplanning and manuscript revision. $\mathrm{H} \mathrm{M}$ - statistical analysis, and manuscript revision. B Z - interpretaion of results and making contributions to the conception of this study. Q M - performing the operation and providing data for this manuscript. All authors have read and approved this manuscript.

\section{Funding}

There was no funding for this study.

\section{Availability of data and materials}

All data are available from the corresponding author on reasonable request.

\section{Ethics approval and consent to participate}

This study has been granted an exemption from requiring ethics approval according to "The ethics committee of Peking Union Medical College Hospital".

\section{Consent for publication}

Not applicable.

\section{Competing interests}

$L M, Y G, H M, B Z$ and $Q$ M declare that they have no competing interests.

\section{Author details}

${ }^{1}$ Department of Anesthesiology, Peking Union Medical College Hospital, Chinese Academy of Medical Sciences and Peking Union Medical College, Beijing 100730, China. ${ }^{2}$ Department of Infectious Diseases, Peking Union Medical College Hospital, Chinese Academy of Medical Sciences and Peking Union Medical College, Beijing 100730, China. ${ }^{3}$ Department of Anesthesia, Critical Care and Pain Medicine, Beth Isreal Deaconess Medical Center,

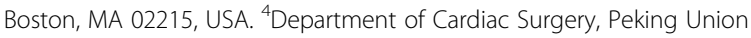
Medical College Hospital, Chinese Academy of Medical Sciences and Peking Union Medical College, Beijing 100730, China.

Received: 22 January 2020 Accepted: 2 June 2020

Published online: 10 June 2020

\section{References}

1. Hoen B, Alla F, Selton-Suty C, Béguinot I, Bouvet A, Briançon S, et al. Vandenesch F; association pour l'Etude et la Prévention de l'Endocardite Infectieuse (AEPEI) study group. Changing profile of infective endocarditis. Results of a 1-year survey in France. JAMA. 2002;288(1):75-81.

2. Cabell CH, Jollis JG, Peterson GE, Corey GR, Anderson DJ, Sexton DJ, et al. Changing patient characteristics and the effect on mortality in endocarditis. Arch Intern Med. 2002;162(1):90-4.

3. Nissen $\mathrm{H}$, Nielsen PF, Frederiksen M, Helleberg C, Nielsen JS. Native valve infective endocarditis in the general population: a 10-year survey of the clinical picture during the 1980s. Eur Heart J. 1992;13(7):872-7.

4. Benn M, Hagelskjar LH, Tvede M. Infective endocarditis, 1984 through 1993: a clinical and microbiological survey. J Intern Med. 1997;242(1):15-22.

5. Friedman ND, Kaye KS, Stout JE, McGarry SA, Trivette SL, Briggs JP, et al. Health care-associated bloodstream infections in adults: a reason to change the accepted definition of community-acquired infections. Ann Intern Med. 2002;137:791-7.

6. Baddour LM, Wilson WR, Bayer AS, Fowler VG Jr, Tleyjeh IM, Rybak MJ, et al. American Heart Association Committee on rheumatic fever, endocarditis, and Kawasaki disease of the council on cardiovascular disease in the young, council on clinical cardiology, council on cardiovascular surgery and anesthesia, and stroke council. Infective endocarditis in adults: diagnosis, antimicrobial therapy, and management of complications a scientific statement for healthcare professionals from the American Heart Association. Circulation. 2015;132:1435-86.

7. Habib G, Lancellotti P, Antunes MJ, Bongiorni MG, Casalta JP, Del Zotti F, et al. ESC scientific document group. 2015 ESC guidelines for the management of infective endocarditis. Eur Heart J. 2015;36:3075-123.

8. Hase R, Otsuka Y, Yoshida K, Hosokawa N. Profile of infective endocarditis at a tertiary -care hospital in Japan over a 14- year period: characteristics, outcome and predictors for in-hospital mortality. Int J Infect Dis. 2015;33:62-6.

9. Murdoch DR, Corey GR, Hoen B, Miró JM, Fowler VG Jr, Bayer AS, et al. International collaboration on endocarditis-prospective cohort study (ICE-
PCS) investigators. Clinical presentation, etiology, and outcome of infective endocarditis in the 21st century: the international collaboration on endocarditis-prospective cohort study. Arch Intern Med. 2009;169(5):463-73.

10. Nakatani S, Mitsutake K, Ohara T, Kokubo Y, Yamamoto H, Hanai S. CADRE investigators. Recent picture of infective endocarditis in Japan-lessons from cardiac disease registration (CADRE-IE). Circ J. 2013;77(6):1558-64.

11. Li L, Wang H, Wang L, Pu J, Zhao $H$. Changing profile of infective endocarditis: a Clinicopathologic study of 220 patients in a single medical center from 1998 through 2009. Tex Heart Inst J. 2014;41(5):491-8.

12. $\mathrm{Xu} \mathrm{H}$, Cai $\mathrm{S}, \mathrm{Dai} \mathrm{H}$. Characteristics of infective endocarditis in a tertiary hospital in East China. PLoS One. 2016;11(11):e0166764.

13. Mirabel M, Rattanavong S, Frichitthavong K, Chu V, Kesone P, Thongsith P, et al. Infective endocarditis in the Lao PDR: clinical characteristics and outcomes in a developing country. Int J Cardiol. 2015;180:270-3.

14. Fowler VG Jr, Miro JM, Hoen B, Cabell CH, Abrutyn E, Rubinstein E, et al. ICE investigators. Staphylococcus aureus endocarditis: a consequence of medical progress. JAMA. 2005;293(24):3012-21.

15. Katsouli A, Massad MG. Current issues in the diagnosis and management of blood culture-negative infective and non-infective endocarditis. Ann Thorac Surg. 2013;95(4):1467-74

16. Cheng J, Hu H, Kang Y, Chen W, Fang W, Wang K, et al. Identification of pathogens in culture-negative infective endocarditis cases by metagenomic analysis. Ann Clin Microbiol Antimicrob. 2018;17(1):43.

17. Fukui $Y$, Aoki K, Okuma S, Sato T, Ishii Y, Tateda K. Metagenomic analysis for detecting pathogens in culture-negative infective endocarditis. J Infect Chemother. 2015:21(2):882-4

18. Durante-Mangoni E, Bradley S, Selton-Suty C, Tripodi MF, Barsic B, Bouza E, et al. International collaboration on endocarditis prospective cohort study group. Current features of infective endocarditis in elderly patients: results of the international collaboration on endocarditis prospective cohort study. Arch Intern Med. 2008;168(19):2095-103.

19. Weber C, Rahmanian PB, Nitsche M, Gassa A, Eghbalzadeh K, Hamacher S, et al. Higher incidence of perivalvular abscess determines perioperative clinical outcome in patients undergoing surgery for prosthetic valve endocarditis. BMC Cardiovasc Disord. 2020;20(1):47.

20. N'Guyen Y, Duval X, Revest M, Saada M, Erpelding ML, Selton-Suty C, et al. Time interval between infective endocarditis first symptoms and diagnosis: relationship to infective endocarditis characteristics, microorganisms and prognosis. Ann Med. 2017;49(2):117-25.

21. Doig F, Loewenthal M, Lai K, Mejia R, lyengar A. Infective endocarditis: a hunter New England perspective. Intern Med J. 2018;48(9):1109-16.

22. Chu VH, Cabell CH, Benjamin DK Jr, Kuniholm EF, Fowler VG Jr, Engemann J, et al. Early predictors of in-hospital death in infective endocarditis. Circulation. 2004;109(14):1745-9.

23. Hill EE, Peetermans WE, Vanderschueren S, Claus P, Herregods MC, Herijgers $P$. Methicillin-resistant versus methicillin-sensitive Staphylococcus aureus infective endocarditis. Eur J Clin Microbiol Infect Dis. 2008;27(6):445-50.

24. Sy RW, Kritharides L. Health care exposure and age in infective endocarditis: results of a contemporary population-based profile of 1536 patients in Australia. Eur Heart J. 2010;31(15):1890-7.

25. Takayama Y, Okamoto R, Sunakawa K. Definite infective endocarditis: clinical and microbiological features of 155 episodes in one Japanese university hospital. J Formos Med Assoc. 2010;109(11):788-99.

26. Moore B, Cao J, Kotchetkova I, Celermajer DS. Incidence, predictors and outcomes of infective endocarditis in a contemporary adult heart disease population. Int J Cardiol. 2017;249:161-5.

27. Benvenga RM, De Rosa R, Silverio A, Matturro R, Zambrano C, Masullo A, et al. Infective endocarsitis and diabetes mellitus: results from a singlecenter study from 1994 to 2017. PLoS One. 2019;14(11):e0223710.

28. Yoshioka D, Toda K, Yokoyama JY, Matsuura R, Miyagawa S, Kainuma S, et al. Osaka cardiovascular research group study group, Sawa Y. diabetes mellitus adversely affects mortality and recurrence after valve surgery for infective endocarditis. J Thorac Cardiovasc Surg. 2018;155(3):1021-9.

29. Khan MZ, Munir MB, Khan MU, Khan SU, Benjamin MM, Balla S. Contemporary trends in native valve infective endocarditis in United States (from the national inpatient sample database). Am J Cardiol. 2020;125(11):1678 [Epub ahead of print].

\section{Publisher's Note}

Springer Nature remains neutral with regard to jurisdictional claims in published maps and institutional affiliations. 